\title{
Epidemiology of Non-Malignant Oral Lesions in a Rural Population Attending a Tertiary Care Centre in Lucknow, U.P., India
}

\author{
Ekta Agarwal' ${ }^{1}$,Sumit Sharma ${ }^{2}$, Ahmed Aseem Naseem ${ }^{3}$ \\ ${ }^{1}$ Senior Resident; ${ }^{2}$ Associate Professor, ${ }^{3}$ Assistant Professor; \\ Department of ENT, Mayo Institute of Medical Sciences, Barabanki
}

Corresponding Author: Sumit Sharma

\begin{abstract}
Objective: To describe the epidemiology of non-malignant oral lesions in a rural population attending a tertiary care centre in Lucknow, India.

Method: A total of 340 patients presenting with oral lesions for more than 2 weeks were enrolled in the study. Patients with proven malignancy, white patch in the oral cavity which can be scrapped off, e.g. oral candidiasis and urban patients were excluded from the assessment. Demographic profile, adverse oral habits and dietary habits of patients were noted. Data was analyzed using SPSS 21.0 software. Data has been represented as number and percentages.

Results: Age of patients enrolled in the study ranged between 18 and 75 years, median age was 32 years and mean age was $33.86 \pm 10.65$ years. Majority were aged 26-50 years $(66.2 \%)$, were males (55.3\%), were farmers/labourers $(58.6 \%)$, were illiterate/educated upto primary grade $(57.1 \%)$. Oral pain and burning sensation was the most common presenting complaint $(45 \%)$. All the patients have two or more of the following habits - areca nut chewing, tobacco chewing and smoking. A total of $41.5 \%$ patients had all the three habits. Alcohol and spicy food consumption were reported by $12.6 \%$ and $84.4 \%$ patients. On histopathology, a total of $191(56.18 \%)$ cases had premalignant lesions and 149 (43.82\%) had benign lesions. Major premalignant types were leukoplakia $(\mathrm{n}=87$; $45.5 \%)$, OSMF $(\mathrm{n}=62 ; 32.5 \%) \quad$ and Erythroplakia $(\mathrm{n}=18 ; 9.4 \%)$. Aphthous ulcer major $(\mathrm{n}=74 ; 49.7 \%)$, geographical tongue $(n=43 ; 28.9 \%)$ and traumatic ulcer $(n=23$; $15.4 \%$ ) were the major benign lesions.
\end{abstract}

Conclusion: In a rural population presenting with non-premalignant oral lesions areca nut, chewing tobacco and smoking were the major etiologies affecting mainly young adults. The high prevalence of premalignant lesions showed a high potential of their transformation to malignant status. Preventive measures with modification of oral habits are recommended.

Key Words: Non-malignant oral lesions, Leukoplakia, oral submucous fibrosis, aphthous ulcer major, rural.

\section{INTRODUCTION}

Oral mucosa is soft and tender and prone to a number of conditions that end up in giving rise to lesions. The oral mucosal lesions can be simple, harmless conditions like ulcerative lesions that tend to heal within 10-14 days without the need of any intervention ${ }^{1}$, however, there are a number of lesions that have potential to become malignant. 2 Consequently, not all oral lesions are oral cancers yet there are oral lesions that have potential to progress into cancerous lesions. Unfortunately, while plenty of literature is available regarding oral malignant and premalignant lesions, there are fewer reports discussing the spectrum of non-malignant and benign oral lesions. The present study tries to focus mainly on non-malignant oral lesions and tries to determine the frequency of benign and premalignant conditions in a rural population of North India. 


\section{MATERIAL AND METHOD}

The present study was carried out as a cross-sectional study in the Department of Otorhinolaryngology, Era's Lucknow Medical College \& Hospital, Lucknow over a period starting from January, 2016 to June, 2017 after approval from Institutional Ethics Committee and obtaining consent from all the participants. A total of 450 patients attending the Outpatient Department of Otolaryngology of Era's Lucknow Medical College and Hospital, having complaints suggestive of oral cavity lesions for more than 2 weeks were included in the assessment. Proven cases of oral malignancy and patients with white patch in the oral cavity which can be scrapped off, e.g. oral candidiasis were excluded from the assessment.

Personal and clinical history of the patients was obtained and was recorded on a Case Record form for each individual, patients were subjected to necessary laboratory and radiographic investigations and biopsy was taken from the lesion and was sent for histopathological examination.

The patient was made comfortable and a detailed history of his complaints was taken on a Case record form designed for the same.

The standard procedure of examination of ear, nose, throat, oral cavity, face and neck was carried out on each patient according to the protocol followed in the Outpatient Department of Otolaryngology, Era's Lucknow Medical College, Lucknow.

Patients were explained about the study and written and informed consent was taken for participation in the study.

Xylocaine sensitivity with $2 \%$ was done Intradermal and tetanus injection was injected intra muscularly before taking the biopsy.

Local was infiltrated around the site of lesion.

Punch biopsy was taken from the site of lesion and was sent for histopathological examination.
Data was analyzed using Statistical Package for Social Sciences (SPSS) version 21.0. Data was represented as frequency (number) and proportions (percentage) and mean \pm SD

\section{RESULTS}

Age of patients enrolled in the study ranged between 18 and 75 years, median age was 32 years and mean age was $33.86 \pm 10.65$ years. Majority were aged 2650 years $(66.2 \%)$, were males $(55.3 \%)$, were farmers / labourers (\%), were illiterate / educated upto primary grade $(51 \%)$ (Table $1)$.

Table 1: Demographic Profile and Characteristics of Study Population

\begin{tabular}{|c|c|c|}
\hline SN & Characteristic & Statistic \\
\hline 1. & $\begin{array}{l}\text { Mean Age } \pm S D \text { (Range) in } \\
\text { years }\end{array}$ & $33.86 \pm 10.65(18-75)$ \\
\hline 2. & Male: Female & $\begin{array}{c}249(55.3 \%): 201 \\
(44.7 \%)\end{array}$ \\
\hline \multirow[t]{8}{*}{3.} & Occupation & \\
\hline & Housewife & $128(28.4 \%)$ \\
\hline & Shopkeeper/Business & $33(7.3 \%)$ \\
\hline & Farmer & $91(20.2 \%)$ \\
\hline & Skilled Labourer & $38(8.4 \%)$ \\
\hline & Unskilled Labourer & $101(22.4 \%)$ \\
\hline & Service & $41(9.1 \%)$ \\
\hline & Student & $62(13.8 \%)$ \\
\hline \multirow[t]{6}{*}{4.} & Education & \\
\hline & Illiterate & $114(25.3 \%)$ \\
\hline & Primary & $143(31.8 \%)$ \\
\hline & Middle-High School & $107(23.8 \%)$ \\
\hline & Intermediate & $49(10.9 \%)$ \\
\hline & Graduate or above & $41(9.1 \%)$ \\
\hline
\end{tabular}

Table 2: Presenting Complaints and Oral Habits

\begin{tabular}{|c|c|c|c|}
\hline SN & Characteristic & No. & $\%$ \\
\hline \multirow{1}{*}{1.} & Presenting Complaints & & \\
\cline { 2 - 4 } & Change of taste & 21 & 4.67 \\
\cline { 2 - 4 } & Dryness of mouth & 37 & 8.22 \\
\cline { 2 - 4 } & Growth in oral cavity & 12 & 2.67 \\
\cline { 2 - 4 } & History of denture use & 20 & 4.44 \\
\cline { 2 - 4 } & Oral pain and burning sensation & 203 & 45.11 \\
\cline { 2 - 4 } & Progressive inability to open mouth & 57 & 12.67 \\
\cline { 2 - 4 } 2. & Whitish patch in oral cavity & 101 & 22.44 \\
\cline { 2 - 4 } & Personal Habits/Risks & & \\
\cline { 2 - 4 } & Smoking & 256 & 56.89 \\
\cline { 2 - 4 } & Areca Nut & 253 & 56.22 \\
\cline { 2 - 4 } & Tobacco chewing & 257 & 57.11 \\
\cline { 2 - 4 } & Smoking + Areca nut/Tobacco & 187 & 41.56 \\
\cline { 2 - 4 } & Ahewing & 144 & 32.00 \\
\cline { 2 - 4 } & Areca nut + Tobacco chewing & 131 & 29.11 \\
\cline { 2 - 4 } & Areca nut + Smoking & 57 & 12.67 \\
\hline Alcohol & 380 & 84.44 \\
\hline
\end{tabular}

Oral pain and burning sensation was the most common presenting complaint $(45.11 \%)$. All the patients have two or more of the following habits - areca nut chewing, 
tobacco chewing and smoking. A total of $41.56 \%$ patients had all the three habits. Alcohol and spicy food consumption were reported by $12.67 \%$ and $84.44 \%$ patients (Table 2).

On histopathology, a total of 253 $(56.22 \%)$ cases had premalignant lesions and 197 (43.78\%) had benign lesions. Major premalignant types were leukoplakia $(\mathrm{n}=115 ; 45.45 \%)$, OSMF $(\mathrm{n}=82 ; 32.41 \%)$ and Erythroplakia $(\mathrm{n}=24 ; 9.49 \%)$. Aphthous ulcer major $(n=98 ; 49.75 \%)$, geographical tongue $(\mathrm{n}=47 ; 28.93 \%)$ and traumatic ulcer $(n=30 ; 15.23 \%)$ were the major benign lesions (Table 3).

Table 3: Spectrum of non-malignant (premalignant and benign) oral lesions

\begin{tabular}{|c|l|c|c|}
\hline Group & \multicolumn{1}{|c|}{ HPE Diagnosis } & No. & \% \\
\hline \multirow{4}{*}{$\begin{array}{c}\text { Premalignant }- \\
(\mathrm{n}=253 ; 56.22 \%)\end{array}$} & Actinic keratosis & 1 & 0.40 \\
\cline { 2 - 4 } & Erythroplakia & 24 & 9.49 \\
\cline { 2 - 4 } & Leukoplakia & 115 & 45.45 \\
\cline { 2 - 4 } & Lichen Planus & 20 & 7.91 \\
\cline { 2 - 4 } & Melanoplakia/Melanosis & 11 & 4.35 \\
\cline { 2 - 4 } & OSMF & 82 & 32.41 \\
\hline \multirow{4}{*}{$\begin{array}{c}\text { Non-premalignant/ } \\
\text { Benign }\end{array}$} & Apthous ulcers major & 98 & 49.75 \\
\cline { 2 - 4 } & Geographical tongue & 57 & 28.93 \\
\cline { 2 - 4 } & Mucocele & 4 & 2.03 \\
\cline { 2 - 4 } & Papilloma & 5 & 2.54 \\
\cline { 2 - 4 } & Pyogenic granuloma & 3 & 1.52 \\
\cline { 2 - 4 } & Traumatic ulcer & 30 & 15.23 \\
\hline
\end{tabular}

\section{DISCUSSION}

The purpose of present study was to provide a comprehensive overview of the spectrum of non-malignant lesions of oral mucosa in a rural population and to discuss the demographic profile, risk factors and clinical characteristics of the susceptible population. There are limited studies conducted on the non-malignant and benign lesions of oral mucosa, however, the limited studies available have shown diverse differences thus indicating that the spectrum of oral lesions and patient characteristics is affected by region, per se, on the oral habits, food preferences and exposure to different risk factors. In present study, the age profile of patients ranged from 18 to 75 years with a mean age of 33.86 years. Compared to this, Tortorici et al. ${ }^{3}$ while reporting prevalence and distribution of oral mucosal non-malignant lesions in a Sicilian population reported the age of patients between 13 and 86 years with a mean of
47.16 \pm 17.71 years. Similarly, Allon et al. ${ }^{4}$ in their study describing the clinical characteristics of benign oral mucosal lesions reported the age of patients to be 0.25 to 86 years and mean age as 49.6 years. However, in another study from India, Mehrotra et al $^{2}$ while reporting prevalence of oral pre-malignant and malignant lesions in a population from eastern UP (India) reported mean age of patients with oral premalignant and benign lesions to be 25 years. These findings in general suggest that oral mucosa is at a higher risk of lesions in Indian population even at a younger age. This could be probably owing to difference in oral habits that will be discussed in latter part of this discussion.

The present study showed a predominance of males $(55.3 \%)$ as compared to females $(44.7 \%)$, i.e. a gender ratio of 1.24. Similar gender ratio was also shown by Tortorici et al. ${ }^{3}$ in their study (1.27). Allon et al. ${ }^{4}$ and Mehrotra et al ${ }^{2}$ in their study also reported a male dominance. As far as potentially malignant lesions are concerned, they too are reportedly higher in males as compared to that in females in various studies $5,6,7,8$.

In present study, farmers and unskilled/skilled laborers comprised 51.2\% of total study population and majority were either illiterate or educated upto primary level $(57.1 \%)$. The lower education and occupational profile of the patients is reflective of their rural origin. Previous studies have also shown that lower socioeconomic strata, especially illiterates and less educated and labourers are more susceptible to oral lesions $8,9,10$. The findings of present study thus endorsed the susceptibility of lower socio-economic class towards oral benign and premalignant lesions too.

As far as presenting complaints were concerned, the present study showed Oral pain and burning sensation as the commonest presenting complaint $(45.11 \%)$ followed by whitish patch in oral cavity $(22.44 \%)$ and progressive inability to open mouth $(12.67 \%)$ respectively. The findings 
suggest that the physical manifestations were the major reasons for patients' visit to our facility. Oral pain and burning sensation, whitish patch in oral cavity and restricted mouth opening are some of the conditions associated with a number of common oral lesions such as erythroplakia, leukoplakia, oral submucous fibrosis, etc. ${ }^{11}$, 12, 13. Apart from these ulcerative lesions also tend to present with pain and burning sensation 1. However, pain and burning sensation is a common but non-specific indication.

In present study, most of the patients were exposed to one or more risk factors. The most common independent personal habit was spicy food (84.4\%) while tobacco chewing, areca nut chewing, smoking and alcohol were reported by $57.11 \%, 56.22 \%$, $56.89 \%$ and $12.67 \%$ patients respectively. Tobacco use, particularly smokeless tobacco use is one of the most common risk factors for oral cancer as well as premalignant lesions ${ }^{12,14}$. In fact considering the importance of tobacco use as a dominant risk factor for oral lesions some studies have been conducted solely in this high risk group of tobacco users only ${ }^{10,15,16,17}$. Other workers have also found prevalence of these habits in majority of their patients with premalignant lesions ${ }^{7,}{ }^{18}$. In their study Gupta et al. ${ }^{19}$ also identified $49.5 \%$ of their patients as tobacco chewers, $28 \%$ as pan masala chewers and $22.5 \%$ to be having mixed habits. Thus showing that majority of patients in their study population were tobacco/pan masala chewers. Incidentally, in their study, they did not report of prevalence of smoking habit. Kumar et al. ${ }^{9}$ in their study also reported use of tobacco/gutkha/smoking in $88 \%$ of their patients. Almost none of these studies have enquired about spicy food intake. This dimension was added in present study as we not only assessed the premalignant lesions but also took inflammatory and nonneoplastic/benign pathologies too. A number of studies have found that low $\mathrm{pH}$ high acidic foods such as Indian spicy food have an increased risk of oral ulcers and other non-neoplastic oral lesions ${ }^{20,21}$. Some other studies have also indicated that although spicy foods do not seem to have a causative role but they are certainly instrumental in aggravating the symptoms of the disease and thus influence patients' healthcare seeking behavior. ${ }^{22}$

In present study, majority of cases (56.22\%) had premalignant conditions while remaining 149 (43.78\%) had nonneoplastic/benign inflammatory conditions. Thus prevalence of premalignant conditions was $56.18 \%$ in our study. Compared to this, Kumar et al. ${ }^{13}$ in their study noticed benign/non-neoplastic oral conditions in $32 \%$ of their patients. However, in their study, Joshi and Tailor ${ }^{17}$ found nonneoplastic/ benign oral conditions in $75.1 \%$ of their patients screened for tobaccoassociated oral lesions. Gupta et al. ${ }^{23}$ too in their study, reported of benign lesions to be 3.3 times higher than the premalignant lesions among patients having neoplastic lesions of oral cavity and oropharynx. The high prevalence of premalignant conditions in present study could be attributable to lesser awareness, low education and lower socioeconomic profile of patients. In fact, most of the patients turned to our facility only when primary facilities/home remedies failed to provide any symptomatic relief. The higher prevalence of premalignant conditions in present study thus indicates the need for use of strategic planning to create awareness regarding progressive nature of non-malignant oral lesions towards malignancy and benefit of early identification and treatment.

In present study major premalignant types were Leukoplakia ( $\mathrm{n}=115 ; 45.45 \%)$, $\operatorname{OSMF}(\mathrm{n}=82 ; 32.41 \%)$ and Erythroplakia $(\mathrm{n}=24 ; 9.49 \%)$ while major benign/nonmalignant types were Aphthous ulcer major $(\mathrm{n}=98 ; 49.75 \%)$, geographical tongue $(\mathrm{n}=57$; $28.93 \%)$ and traumatic ulcer $(n=30$; 15.23\%). Similar to our study, Ambedkar et al. ${ }^{15}$ and Mishra et al. ${ }^{16}$, also found Leukoplakia to comprise $37.8 \%$ and $41.6 \%$ of premalignant lesions in their series. Jagtap et al. ${ }^{18}$ in their study found 
Leukoplakia to comprise $68.41 \%$ of their study population. As far as OSMF is concerned, a number of studies have reported it to be dominant premalignant type reporting in $30.4 \%$ to $88.1 \%$ of premalignant lesions $17,10,24,25$. Similar to our study, Tortorici et al. ${ }^{3}$ in their study found also found aphthous ulcer and traumatic ulcers to be quite common nonmalignant benign oral lesions; however, they did not find geographic tongue to be a dominant type. In their study, ulcerative lesions comprised $22 \%$ of total sample. In present study too, ulcerative conditions accounted for nearly $28.5 \%$ of total lesions. However, Allon et al. ${ }^{4}$ who described the clinical characteristics of benign oral mucosal tumors reported the non-ulcerated masses $(98.6 \%)$ to be most common types. However, in their study only biopsy proven cases of benign tumors were taken into consideration. However, ulcerative lesions owing to their presentation with pain and burning sensation are more commonly reported as observed in our study.

In present study, papilloma (2.54\%), mucocele $(2.03 \%)$ and pyogenic granuloma $(1.52 \%)$ were the some of the least common non-malignant benign lesions. These conditions are rare and are generally reported as case reports only $26,27,28$.

The findings of present study conducted amongst rural patients a tertiary care facility thus showed that rural patients generally tend to report late with a high dominance of premalignant conditions or conditions accompanied with pain and burning sensation. A high dominance of premalignant conditions in this study could be attributable to presence of multiple adverse oral habits. It would be pertinent to mention here that malignant conditions were excluded from the study domain. The gravity of situation would have been worse had had malignant lesions also included. These findings in turn indicate a need for strategic interventions to create awareness, strong statutory provisions and upgradation of primary care facilities. The present study was probably the first work on non- malignant lesions in rural setting, further studies on a similar population and a comparative assessment with urban population is recommended to get a clearer picture.

\section{Ethical Considerations of the Study:}

1. Ethics Committee Approval: Ethics committee approval was received for this study from the Institutional Ethics Committee.

2. Written Informed Consent was obtained from concerned subjects and authority of institutions.

3. Privacy, confidentiality and anonymity were granted.

4. Scientific objectivity was maintained with honesty and impartiality.

Authors Contributions: Concept - EA;SS; Design - EA,SS,A.A.; Supervision EA,SS, A.A., Resource - EA, A.A., SS; Materials - EA,SS, A.A.; Data Collection and/or Processing - EA, Analysis and/or Interpretation - EA, SS, A.A.; Literature Search - EA, SS, A.A.; Writing - EA, SS, A.A., Critical Reviews - EA, SS, A.A.

Conflict of Interest: The authors declare that this study has had no conflicts of interest.

Financial Disclosure: The authors declare that this study had received no financial support.

\section{Acknowledgement: None}

\section{REFERENCES}

1. Mortazavi H, Safi Y, Baharvand M, Rahmani S. Diagnostic Features of Common Oral Ulcerative Lesions: An Updated Decision Tree. International Journal of Dentistry. 2016;2016:7278925.

2. Mehrotra R, Pandya S, Chaudhary AK, Kumar M, Singh M. Prevalence of Oral Premalignant and Malignant Lesions at a Tertiary Level Hospital in Allahabad, India. Asian Pacific J Cancer Prev 2008; 9: 263266. 
3. Tortorici S, Corrao S, Natoli G, Difalco P. Prevalence and distribution of oral mucosal non-malignant lesions in the western Sicilian population. Minerva Stomatologica 2016 August;65(4):191-206.

4. Allon I, Kaplan I, Gal G, Chaushu G, Allon DM. The clinical characteristics of benign oral mucosal tumors. Med Oral Patol Oral Cir Bucal. 2014 Sep 1;19 (5):e438-43.

5. Petti S. Pooled estimate of world leukoplakia prevalence: A systematic review. Oral Oncol 2003;39:770-80.

6. Delibasi C, Akman H, Redzep E, Aka UK. Prevalence of Oral Precancerous Lesions in a Selected Turkish Population.Turk J Med Sci 2003; 33: 39-42.

7. Vinay BH, Baghirath PV, Kumar JV, Arvind. Prevalence of precancerous lesions and conditions in Telangana region, Andhra Pradesh, India. J Indian Assoc Public Health Dent 2014;12:23-7.

8. Kaur J, Chopra R, Singh A. To Study The Prevalence Of Precancerous Lesions Of The Oral Cavity At A Tertiary Level Hospital In Faridkot, Punjab (India). Indian Journal of Dental Sciences . 2015; 7(5): 014-019.

9. Kumar A, Birua C, Kant C. A Study on Clinicoetiopathogenesis of Oral Precancerous Lesion in Jharkhand. Int. J. Contemp. Med. Res. 2016; 3(9): 2691-2693.

10. Narasannavar A, Wantamutte AS. Prevalence of oral precancerous lesions and conditions among tobacco consumers in rural population around Belgaum. A community based cross sectional study. IOSR Journal of Dental and Medical Sciences 2014; 13(4-III): 31-34.

11. Neville BW, Damm DD, Allen CM, Bouquot JE. Oral \& maxillofacial pathology. Third ed. Phila., PA: Saunders; 2009; 425-433.

12. Warnakulasuriya S, Reibel J, Bouquot J, Dabelsteen E. Oral epithelial dysplasia classification systems: predictive value, utility, weaknesses and scope for improvement. J Oral Pathol Med 2008 Mar;37(3):127-33.

13. Kumar K, Saraswathi TR, Ranganathan K, Uma Devi M, Elizabeth J. Oral submucous fibrosis: A Clinico-histopathologic study in Chennai. Indian J of Dent Res 2007; 18: 5359.

14. Shenoi R, Devrukhkar V; Chaudhuri, Sharma BK, Sapre SB, Chikhale A. Demographic and clinical profile of oral squamous cell carcinoma patients: a retrospective study. Indian J Cancer. 2012; 49(1): 21-6.

15. Ambekar DM, Chaudhary BJ and Kulkarni VV. A study of prevalence of oral precancerous lesions in relation to tobacco habituation. 2014; 5(1): 282-285.

16. Mishra SS, Kale LM, Sodhi SJ, Mishra PS, Mishra AS. Prevalence of oral premalignant lesions and conditions in patients with tobacco and tobacco-related habits reporting to a dental institution in Aurangabad . J Indian Acad Oral Med Radiol 2014;26:1527.

17. Joshi M, Tailor M. Prevalence of most commonly reported tobacco-associated lesions in central Gujarat: A hospital-based cross-sectional study. Indian J Dent Res 2016;27:405-9.

18. Jagtap SV, Warhate P, Saini N, Jagtap SS, Chougule PG. Oral premalignant lesions: a clinicopathological study. IntSurg J. 2017 Oct;4(10):3477-3481.

19. Gupta S, Singh R, Gupta O P, Tripathi A. Prevalence of oral cancer and pre-cancerous lesions and the association with numerous risk factors in North India: A hospital based study. Natl J MaxillofacSurg 2014;5:142-8.

20. Tarakji B, Baroudi K, Kharma Y. The effect of dietary habits on the development of the recurrent aphthous stomatitis. Nigerian Medical Journal: Journal of the Nigeria Medical Association. 2012;53(1):9-11.

21. Scully C, Porter S. Oral cancer. Western Journal of Medicine. 2001;174(5):348-351.

22. Gonsalves WC, Chi AC, Neville BW. Common Oral Lesions: Part I. Superficial Mucosal Lesions. Am Fam Physician. 2007; 75(4): 501-506.

23. Gupta M, Choudhary H, Gupta N, Gupta A. Histopathological study of neoplastic lesions of oral cavity and oropharynx. Int J Res Med Sci. 2016 May;4(5):1506-1510.

24. Kumar YS, Acharya S, Pentapati KC. Prevalence of oral potentially malignant disorders in workers of Udupi taluk. South Asian J Cancer 2015;4:130-3. Link

25. Kumar S, Debnath N, Ismail MB, Kumar A, Kumar A, Badiyani BK, Dubey PK and Sukhtankar LV. Prevalence and Risk Factors for Oral Potentially Malignant Disorders in Indian Population. Advances in Preventive Medicine 2015; Article ID 208519: 1-7. Link 
Ekta Agarwal et.al. Epidemiology of non-malignant oral lesions in a rural population attending a tertiary care centre in Lucknow, U.P., India.

26. Dos Reis HLB, Rabelo PC, de Santana MRF, Ferreira DC, Filho AC. Oral squamous papilloma and condyloma acuminatum as manifestations of buccalgenital infection by human papillomavirus. Indian Journal of Sexually Transmitted Diseases. 2009;30(1):40-42.

27. Chaitanya P, Praveen D, Reddy M. Mucocele on Lower Lip: A Case Series. Indian Dermatology Online Journal. 2017;8(3):205-207.

28. Gomes SR, Shakir QJ, Thaker PV, Tavadia JK. Pyogenic granuloma of the gingiva: A misnomer? - A case report and review of literature. Journal of Indian Society of Periodontology 2013;17(4):514-519.

How to cite this article: Agarwal E, Sharma S, Naseem AA. Epidemiology of non-malignant oral lesions in a rural population attending a tertiary care centre in Lucknow, U.P., India. International Journal of Research and Review. 2021; 8(6): 1-7. DOI: https://doi.org/10.52403 /ijrr.20210601 